\title{
The Announcement of Unconventional Monetary Policy and the Exit Risk in the European Monetary Union
}

\author{
Paolo Canofari ${ }^{1}$, Alessandra Marcelletti ${ }^{1,2} \&$ Giovanni Piersanti ${ }^{3}$ \\ ${ }^{1}$ Luiss School of European Political Economy, Luiss University, Rome, Italy \\ ${ }^{2}$ Department of Political Science, Luiss University, Rome, Italy \\ ${ }^{3}$ University of Teramo, Teramo, Italy \\ Correspondence: Paolo Canofari, Luiss School of European Political Economy, Luiss University, Via di Villa \\ Emiliani 14, Rome, Italy. Tel: 39-06-8022-22346. E-mail: pcanofari@luiss.it
}

Received: January 27, 2018

Accepted: February 21, 2018

Online Published: March 5, 2018

doi:10.5539/ijef.v10n4p95

URL: https://doi.org/10.5539/ijef.v10n4p95

\begin{abstract}
The introduction of unconventional monetary policy, pushing down the euro value, aims at strengthening the euro area, by increasing its competitiveness and boosting its economic growth. The goal of our paper is to offer a theoretical validation of these facts using a monetary union model in which a representative country and a common central bank strategically interact. The country can choose to stay in or opt out from the monetary union after a demand shock, while the central bank controls the exchange rate to preserve the stability of the union. Our main result is that the announcement of common exchange rate depreciation reduces the probability of a monetary union breakup.
\end{abstract}

Keywords: monetary unions, Nash equilibria, exchange rate, central bank

\section{Introduction}

To restore confidence in the euro area and to restrain the crisis of sovereign debt, the European Central Bank (ECB henceforth) launched a set of non-standard monetary policy measures. These unconventional interventions (OMT programme) started in July 2012 when the President of the ECB Mario Draghi pronounced his famous word "the European Central Bank is ready to do whatever it takes to preserve the euro".

As a part of this measures, in January 2015 the Governing Council announced the introduction of the Expanded Asset Purchase Programme (APP) (Note 1), also known as quantitative easing (QE henceforth).

The immediate market reaction to the announcement was the sharp depreciation of the euro value, the decrease of the sovereign yields, and the increase in the stock market price.

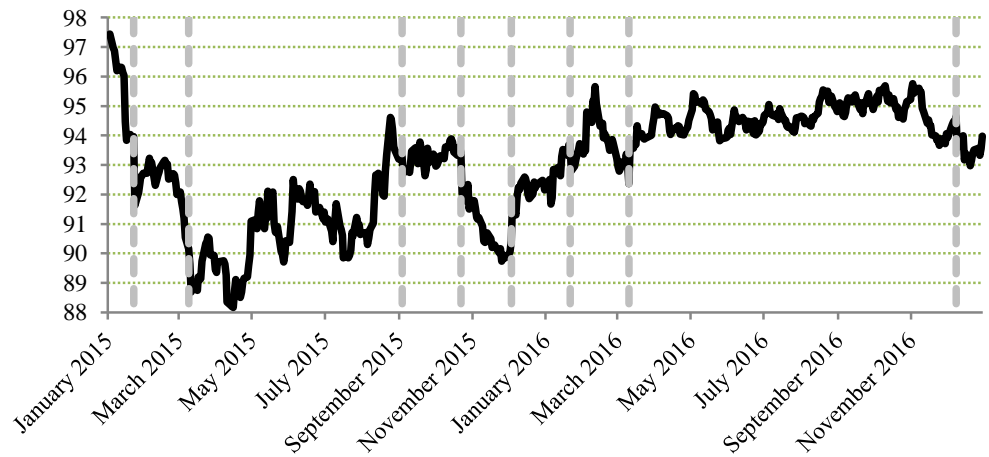

Figure 1. Nominal effective exchange rate and the quantitative easing interventions (index number, 1999Q1=100)

Note. ECB Nominal effective exchange rate (EER-19) of the Euro against a group of 19 partner countries (AU, CA, DK, HK, JP, NO, SG, KR, SE, CH, GB, US, BG, CZ, HU, PL, RO, HR and CN). Source: Statistical Data Warehouse, ECB. The dashed line indicates when the Governing Council announced the APP, and the subsequent recalibrations. 
Figure 1 shows the reaction of the effective exchange rate (over the period 2015-2016), and it displays that the highest downward pressures on this variable were generated by the announcement of the launch of the APP, as well as of its subsequent recalibration. Indeed, the effective exchange rate fell by around $1 \%$ every time the Governing Council announced an adjustment, with a pick of 2,33\% between 22 and 23 of January 2015, i.e. the day after the launch of the programme. To understand the magnitude of this depreciation, it is worth noting that this is the second heaviest loss ever of the euro against the main commercial partner. At the same time, the euro depreciation vis-à-vis the US dollar was about $4 \%$ over the same night. This downward pressure on the euro exchange rate is not surprising, since it is in line with the effect generated by the Large Asset Purchase Programme of the Federal Reserve, and the QE of the Bank of Japan, respectively in US and in Japan.

Regarding the possible effect of the APP on the euro area economy, the announcement of the introduction of non-standard measures plays an important role in the effectiveness of the monetary policy, because it can induce a lower interest rate expectation that, in turn, increases the capital outflow, with a sale of the euro-denominated asset and a depreciation of the exchange rate. These factors increase the competitiveness of the euro area.

The descriptive analysis presented above is confirmed by some empirical studies (e.g. Glick \& Leduc, 2013) showing that the introduction of the APP generated a negative and persistent effect on the euro exchange rate, and confirms the activation of the exchange rate channel in transmitting the monetary policy on the real economy. In particular, Gambetti and Musso (2017) demonstrate that there is a peak of depreciation of about 5\% in the euro exchange rate after two quarters from the introduction of the APP. The reaction of the exchange rate also informs on whether the measures help in restoring price stability in line with the definition of the Governing Council, i.e. below, but close to, $2 \%$ : upward pressure on prices in the euro area can be placed by an increase in the prices of imported goods.

The idea is that the announcement of the quantitative easing (in terms of the APP) by the Governing Council can boost the economy, by triggering the exchange rate channel. In this paper, we rely on these stylized facts about the relationship between the $\mathrm{QE}$ and the exchange rate, to assess the stability of a monetary union, by analyzing the possible impact of the exchange rate on the probability of a euro area breakup. More specifically, this paper internalizes the role of the APP within a theoretical framework which formalizes the expectation of depreciation of the euro. The framework is part of the literature on strategic interactions between countries belonging to fixed exchange rate regimes (e.g., Buiter et al., 1996; Di Bartolomeo et al., 2006), and it is based on the contributions of Canofari et al. (2015a), Canofari and Di Bartolomeo (2017), and Canofari and Messori (2017), cast in the strand of literature aiming to explain the crises of fixed exchange rate regimes (e.g., Krugman, 1979; Obstfeld, 1986, 1994, 1995; Jeanne, 1997; De Grauwe \& Ji, 2013; Canofari et al., 2014, 2015b) (Note 2).

The main innovation is the departure from the standard approach that encompasses a monetary union characterized by the interactions between two (or more) countries, to cast the model in a framework where the focus is on the strategic interactions between the common central bank and a representative country, where the central bank fully controls the exchange rate.

The rest of the paper is organized as follows. Section 2 introduces the theoretical set-up. Section 3 determines the impact of different hypotheses about the exchange rate management by the central bank on the possibility of a country's exit from the monetary union. Section 4 concludes.

\section{The Model Set-Up}

The structure of this stylized model partially reproduces the one used in Canofari et al. (2014, 2015a,b), with a crucial difference: instead of relying on a two-country model, we consider a monetary union characterized by a central bank that strategically interacts with a representative country, say country $A$, which joins the monetary union. To capture the role played by the exchange rate as a channel of transmission of the (unconventional) monetary policy interventions by the common central bank, we assume that the only instrument in the hand of the policymaker, both of country $A$ and of central bank, is the exchange rate with respect to the rest of the world. Although the instrument in the hand of policymakers does not change, the use of it by country $A$ or by central bank implies different scenario for the monetary union: the choice of an exchange rate devaluation/revaluation by country $A$ implies the decision for the country itself to leave the monetary union, while a movement in the common currency exchange rate means that the central bank has undertaken a (non-conventional) monetary interventions. The model's structure also includes the rest of the world, even though in this game we assume that the other countries joining the same monetary union do not react either to the action of country $A$ or to that of the central bank.

Measuring all variable in logs and assuming that country's $A$ economy produces a single internationally traded good, and that prices are fixed, for simplicity, we can write the aggregate supply as (Note 3). 


$$
y_{A}=\alpha\left(s_{A^{-}} s^{*}\right),
$$

where $y_{A}$ is the output gap from a desired target level, here normalized to zero for simplicity, $s_{A}$ the (shadow) nominal exchange rate for country $A$, and $s^{*}$ the relative entry currency parity (Note 4$)$. The nominal exchange rate is defined as the price of the union common currency in terms of the currency of country $A$.

Under fixed prices, the international demand for the goods produced in country $A, d_{A}$, can be assumed to depend on the nominal effective exchange rate (Note 5), namely

$$
d_{A}=\sigma_{\mathrm{A}}\left(s_{A^{-}} \beta s_{W}\right)-u_{A},
$$

where $\sigma_{A}$ is the output elasticity of aggregate demand to the nominal effective exchange rate $\left(s_{A}-\beta s_{W}\right), s_{W}$ the nominal exchange rate of the rest of the world $W$ expressed with respect to the common currency, $\beta$ the weight of the rest of the world for country $A$, and $u_{A}$ an aggregate demand shock that is assumed to affect country A.

Equilibrium in the goods market of the representative country $A$ implies

$$
y_{A}=\sigma_{A}\left(s_{A}-\beta s_{W}\right)-u_{A} .
$$

This equation shows that a depreciation of the common currency (i.e., a negative $s_{W}$ ) results in an increase in the external competitiveness of country $A$ and thus an increase in its output. It also shows an increase in the output of country $A$ if it chooses to abandon the monetary union and devalue its new currency (i.e., a rise in $s_{A}$ ).

Let us now consider the central bank's behavior. Our paper assumes that the central bank's primary objective is maintaining price stability by pursuing an inflation target, here set to zero for simplicity (Note 6). We also assume that the central bank can control the common currency exchange rate with respect to the rest of the world $s_{W}$, and that it represents a cost in terms of inflation for country $A$ and for the central bank itself. This means that the central bank's loss function $(B)$ explicitly considers the possible devaluation of $s_{A}$ that country $A$ can realize once it leaves the monetary union. This cost is internalized by the central bank since it implies that the exit of a country from the monetary union destabilizes the union itself.

Finally, it is assumed that the central bank sustains an additional cost $C_{B}$ in terms of its own credibility, in the event of a common currency break-up $(\delta)$ (Note 7). Thus, the loss function for the central bank can be written as

$$
B=s_{W}^{2}+a s_{A}^{2}+\delta C_{B} \text {. }
$$

As formalized in equation (5) below, the policymaker in country $A$ is supposed to minimizes a loss function $\left(L_{A}\right)$ defined over its output $y_{A}$ and the inflation gap (Note 8), which depend on $s_{A}$ but also on the possible depreciation of the common currency (Note 9) $s_{W}$, weighted for the coefficient $\theta(\theta>0)$ measuring the inflation aversion. Country's $A$ policymaker also takes into account the potential loss of international credibility in case of exit from the monetary union, and this is why we added the exogenous term cost $C$ to equation (5) (Note 10):

$$
L_{A}=y_{A}^{2}+\theta_{A}\left(s_{A}-\beta s_{W}\right)^{2}+\delta C .
$$

Substituting (3) into (5) and minimizing with respect to the exchange rate, we obtain the reaction function of country $A$, expressed in terms of optimal devaluation given the common currency depreciation and the country specific shock:

$$
S_{A}=\beta S_{w}+\frac{\sigma_{A} U_{A}}{\sigma_{A}^{2}+\theta_{A}}
$$

Equation (6) shows that the higher the shock $u_{A}$, the higher is the country $A$ 's devaluation in the case of an exit from the monetary union. At the same time, the greater the common currency depreciation induced by the central bank, the lower the devaluation in the case of country $A$ 's exit.

Let us now analyse the central bank's problem. If the central bank plays Nash, it simply minimizes (4) with respect to $s_{W}$. In such a case, it is easy to verify that the central bank will prefer to set $s_{W}=0$, which implies, given (6), the highest devaluation for country $A$ under the exit occurrence.

Alternatively, if the central makes an announcement of currency depreciation (Note 11), it internalizes the reaction function of country $A$ (i.e., equation (6)). In other words, it considers the effect of the common currency depreciation on the behaviour of country $A$. In such a scenario, the central bank's problem becomes minimizing (5) with respect to $s_{W}$ under the constraint (6). The resulting depreciation for the common currency is now.

$$
S_{W}=-\frac{\alpha \beta \sigma_{A} U_{A}}{\left(\sigma_{A}^{2}+\theta_{A}\right)\left(1+\alpha \beta^{2}\right)}
$$

which shows that the higher the shock level, the higher the common currency depreciation (Note 12). 
Substituting (7) into (6), we obtain the optimal devaluation for country $A$ in the event of its exit, given the shock and the central bank's commitment:

$$
S_{A}=\frac{\sigma_{A} U_{A}}{\left(\sigma_{A}^{2}+\theta_{A}\right)\left(1+\alpha \beta^{2}\right)}
$$

Equation (8) shows, once again, that the higher the shock level is, the higher the devaluation for country $A$ will be.

\section{The Role of Policy of the Central Bank}

In this section, we analyse the impact that the commitment to a common currency depreciation played by the central bank has on country $A$ 's exit probability, compared to the case in which the central bank plays Nash without announcements.

As in Canofari et al. (2015a) two different régimes can occur (Note 13). In the first one, country A, even if affected by the shock, chooses to remain in the monetary union. In the second one, country A may be induced to leave the common currency, if the shock is large enough. In this paper, we assume that the fact that country A abandons the monetary union is enough to destabilize the whole currency area. For this reason, the central bank is motivated to prevent the exit of country $A$.

\subsection{The Absence of a Central Bank's Commitment: The Nash Equilibrium}

In this scenario, the central bank does not announce any monetary intervention so that the exchange rate channel is not activated. As shown below, this is modelled by letting the central bank play Nash against country $A$ and set $s_{W}=0$, implying the highest devaluation for country $A$. To check, set $s_{W}=0$ in (6) and find that the reaction function for country $A$ to the decision of the central bank is

$$
S_{A}=\frac{\sigma_{A} U_{A}}{\sigma_{A}^{2}+\theta_{A}}
$$

which results in the highest value for $s_{A}$.

To understand the country $A$ 's (optimal) decision in this scenario, we compare the loss country $A$ incurs when it decides to opt out from $\left(L_{D A}^{N}\right)$ or stay in $\left(L_{A}^{N}\right)$ the monetary union. The first can be computed by substituting equation (9) and $S_{W}=0$ in the general formulation of the lossn function given in equation (5), to obtain

$$
L_{D A}^{N}=\frac{\left(u_{A}^{2}+C\right) \theta_{A}+C \sigma_{A}^{2}}{\sigma_{A}^{2}+\theta_{A}} .
$$

The second, implying that the central bank does not intervene and country $A$ remains in the common currency, can be computed setting $S_{W}=S_{A}=0$ in equation (5), to yield

$$
L_{A}^{N}=u_{A}^{2} \text {. }
$$

Solving $L_{A}^{N}-L_{D A}^{N}=0$ for the exogenous observed shock level, gives the threshold level $v^{N}$ at which country $A$ is indifferent between staying in or leaving the monetary union:

$$
v^{N}=\frac{\sqrt{\theta_{A}\left(\theta_{A}+\sigma_{A}^{2}\right) C}}{\sigma_{A}} .
$$

If the actual shock exceeds $v^{N}, L_{A}^{N}-L_{D A}^{N}>0$ and country $A$ will optimally chooses to leave the monetary union.

\subsection{The Central Bank's Commitment}

If the central bank commits itself to depreciate the common currency, it internalizes the reaction of country $A$ to its policy. In this case, the loss for country $A$ in the event of exit, $L_{D A}^{B}$, can be computed substituting (7) and (8) into (5), to get

$$
L_{D A}^{B}=\frac{\left(u_{A}^{2}+C\right) \theta_{A}+C \sigma_{A}^{2}}{\sigma_{A}^{2}+\theta_{A}},
$$

which equals the loss in the absence of commitment $L_{D A}^{N}$ (see equation (10)).

Alternatively, if country $A$ remains in the monetary union, the loss $\left(L_{A}^{B}\right)$ is

$$
L_{A}^{B}=\frac{\left(1+a \beta^{2}\right)^{2} \theta_{A}+\sigma_{A}^{2}}{\left(\sigma_{A}^{2}+\theta_{A}\right)\left(1+a \beta^{2}\right)^{2}} u_{A}^{2} .
$$


Again, solving $L_{D A}^{B}-L_{A}^{B}=0$ for the shock level, the threshold level $v^{B}$ at which country $A$ is indifferent between staying in or opt out of the monetary union under commitment can be computed as

$$
v^{B}=\frac{\sqrt{\left(\theta_{A}+\sigma_{A}^{2}\right) c\left(1+a \beta^{2}\right)}}{\sigma_{A}} .
$$

It is easy to check that $v^{B}$ is greater than $v^{N}$, for

$$
\frac{v^{B}}{v^{N}}=1+a \beta^{2}>1
$$

This means that under the central bank's commitment to depreciate the common currency, the loss for country $A$ will be lower than when the central bank acts without a commitment. Therefore, if the central bank announces a depreciation of the common currency, in order to induce country $A$ to leave the monetary union the shock must be higher. In other words, the welfare of a country joining and further deciding to stay in a monetary union improves with a common central bank's commitment.

\section{Conclusion}

This paper innovates the framework developed by Canofari et al. (2015a, 2017) and Canofari and Messori (2017). We mainly contribute to the current literature and policy debate by allowing for strategic interactions between a representative country and a common central bank in a monetary union. Accordingly, the focus is not on the possible contagion effects of an aggregate demand shock on a two-country model setup for a monetary union, but on the possible outcomes that follow from the central bank reaction to the shock itself. From a policy perspective, the stylized facts we refer to are under which conditions the quantitative easing can strengthen the monetary union, and therefore we offer a theoretical justification for announcing an unconventional monetary intervention to promote and sustain the stability within the European Monetary Union.

The paper assesses the impact of a common currency exchange rate policy. The main result is that if the central bank announces an exchange rate depreciation that can be thought of as a non-standard monetary policy intervention, the loss for the country under consideration is reduced if it stays in the common currency area, making its exit less likely relative to the case in which the central bank plays Nash without commitment. We also derived threshold values for an observed aggregate demand shock, identifying different regimes. If the shock is large enough, the country affected by the shock leaves the monetary union.

The theoretical results obtained in this stylized model show that the central bank's credible commitment to a common currency depreciation can reduce the instability of the monetary union. From this point of view, the Quantitative Easing program, which implies the expectation of depreciation for the common currency, represents a mechanism strengthening the Eurozone.

\section{References}

Buiter, W. H., Corsetti, G., \& Pesenti, P. (1996). Interpreting the ERM Crisis: Country-Specific and Systemic Issue. CEPR Discussion Paper, 1466 (October), London: CEPR. Retrieved from http://eprints.lse.ac.uk/20361/

Canofari, P., \& Di Bartolomeo, G. (2017). Regime Switches under Policy Uncertainty in Monetary Unions. European Journal of Political Economy, 47, 124-132. https://doi.org/10.1016/j.ejpoleco.2016.08.007

Canofari, P., \& Messori, M. (2017). Exit Risks and Contagion in the Euro Area. Economic Modeling, https://doi.org/10.1016/j.econmod.2017.09.007

Canofari, P., Di Bartolomeo, G., \& Piersanti, G. (2015a). Strategic Interactions and Contagion Effects under Monetary Unions. The World Economy, 38(10), 1618-1629. https://doi.org/10.1111/twec.12281

Canofari, P., Marini, G., \& Piersanti, G. (2014). Measuring Currency Pressure and Contagion Risks in Countries under Monetary Unions: The Case of Euro. Atlantic Economic Journal, 42(4), 455-69. https://doi.org/10.1007/s11293-014-9434-2

Canofari, P., Marini, G., \& Piersanti, G. (2015b). Expectations and Systemic Risk in EMU Government Bond Spreads. Quantitative Finance, 15(4), 711-724. https://doi.org/10.1080/14697688.2014.968606

De Grauwe, P., \& Ji, Y. (2013). Self-Fulfilling Crises in the Eurozone: An Empirical Test. Journal of International Money and Finance, 34, 15-36. https://doi.org/10.1016/j.jimonfin.2012.11.003

Di Bartolomeo, G., Engwerda, J., Plasmans, J. \& van Aarle, B. (2006). Stying Together or Breaking Apart: Policy-makers' Endogenous Coalitions Formation in the European Economic and Monetary Union. Computers \& Operations Research, 33(2), 438-463. https://doi.org/10.1016/j.cor.2004.06.015 
Gambetti, L., Musso, A. (2017). The macroeconomic impact of the ECB's expanded asset purchase programme (APP). ECB Working Paper No. 2075/June 2017.

Glick, R., \& Leduc, S. (2013). The effects of unconventional and conventional U.S. monetary policy on the dollar. Working Paper Series 2013-11, Federal Reserve Bank of San Francisco.

Jeanne, O. (1997). Are Currency Crises Self-Fulfilling? A Test. Journal of International Economics, 43(3-4), 263-86. https://doi.org/10.1016/S0022-1996(97)00002-0

Krugman, P. R. (1979). A Model of Balance-of-Payments Crises. Journal of Money, Credit and Banking, 11(3), $311-25$.

Obstfeld, M. (1986). Rational and Self-Fulfilling Balance of Payments Crises. American Economic Review, 76(1), 72-81.

Obstfeld, M. (1994). The Logic of Currency Crises. Cahiers Économiques et Monétaires, 43(1), 189-213.

Obstfeld, M. (1997). Destabilizing Effects of Exchange-Rate Escape Clauses. Journal of International Economics, 43(1-2), 61-77. https://doi.org/10.1016/S0022-1996(96)01460-2

Piersanti, G. (2012). The Macroeconomic Theory of Exchange Rate Crises. Oxford: Oxford University Press.

\section{Notes}

Note 1. The Asset Purchase Program was announced on 22 January 2015 and was launched the $5^{\text {th }}$ of March 2015, and it further includes a public sector asset purchase programme (PSPP).

Note 2. A detailed analytical discussion of the existing theoretical literature on currency crises can be found in Piersanti (2012).

Note 3. More details are found, e.g., in Canofari et al. (2014).

Note 4. The shadow exchange rate is here the floating rate that would prevail at any date $t$ in country $A$ conditional on exit from the monetary union. The key role this variable plays in the theory of exchange rate crises is described in Piersanti (2012).

Note 5. The reason is that under fixed price, a change in the nominal exchange rate leads to a change in the real exchange rate and hence in competitiveness.

Note 6. We recall that in the eurozone the primary objective of the ECB's monetary policy is to maintain price stability, and that to best service this objective the ECB aims at inflation rates of below, but close to, $2 \%$ over the medium term.

Note 7. $\delta$ is a dummy variable, equal to 1 if the country leaves the monetary union and 0 otherwise.

Note 8 . In this paper, we assume that in a monetary union the only source of inflation is represented by the common currency depreciation and by the devaluation of country $A$ once it chooses to leave the monetary union.

Note 9. For simplicity, we assume that the impact of the depreciation of the common currency on country $A$ 's inflation is exactly $\beta$.

Note 10. This cost can be considered as a proxy for all the costs other than inflation that the country sustains when it decides to leave the monetary union (e.g., banking crises, government debt sustainability, voter dissension, or even government's removal from the office).

Note 11. See, for example, the QE programme setting off expectations of a euro depreciation.

Note 12. It is worth reminding that a depreciation implies a negative $s_{W}$.

Note 13. For the sake of completeness, we can also report that Canofari et al. (2015a) demonstrate the existence of a third régime, where two countries leave the monetary union. Obviously, we are not interested in this case since we have only a representative country in our model. Our assumption is that one country exit is enough to destabilize the whole monetary union.

\section{Copyrights}

Copyright for this article is retained by the author(s), with first publication rights granted to the journal.

This is an open-access article distributed under the terms and conditions of the Creative Commons Attribution license (http://creativecommons.org/licenses/by/4.0/). 